\title{
A study of Happiness in the Islamic Republic of Iran's work communities
}

\author{
Behzad Damari ${ }^{1}$, Hossain Almadani ${ }^{1}$, Hossein Mirzaei $^{2 *}$ (1) \\ Received: 29 Oct 2018 Published: 6 Apr 2021
}

\begin{abstract}
Background: Happiness, a factor in social, political, and economic development, leads to higher performance, increase in production, and great efficiency. The goal of this study was to assess the level of happiness in Iran's work communities.

Methods: In this cross-sectional survey study, we randomly selected 13842 people from 380 workplaces in 31 provinces of Iran. Trained interviewers based on structured questionnaires collected data. Reliability of the questionnaire determined by using internal consistency. Collected data were analyzed through SPSS 16 software (SPSS Inc., Chicago, IL) and the charts and tables were prepared to indicate each province's happiness level and the national mean.

Results: Average age of employees was $35.4 \pm 7.78$ years. The majority of the respondents were male $(\mathrm{n}=11835,85.5 \%)$, had finished middle/secondary school $(\mathrm{n}=7142,51.6 \%)$ and were married $(\mathrm{n}=11323,81.8 \%)$. The level of happiness varied from the highest value 148.97 \pm 21.49 in Boushehr Province and the lowest $130.39 \pm 25.28$ in Hormozgan Province. The mean \pm SD value of happiness in the work communities of Iran was $141.22 \pm 22.89$.
\end{abstract}

Conclusion: Policymakers should consider workers' happiness as an effective factor in production and efficiency.

Keywords: Happiness, Workplace, Iran

Conflicts of Interest: None declared

Funding: State Welfare Organization of Iran

\section{*This work has been published under CC BY-NC-SA 1.0 license. \\ Copyright $\odot$ Iran University of Medical Sciences}

Cite this article as: Damari B, Almadani H, Mirzaei H. A study of Happiness in the Islamic Republic of Iran's work communities. Med J Islam Repub Iran. 2021 (6 Apr);35:45. https://doi.org/10.47176/mjiri.35.45

\section{Introduction}

Happiness, a factor in social, political, and economic development, may lead to higher performance and an increase in production and efficiency. Providing stability in the workplace and reducing the tensions, it can produce a significant effect on employees' morale (1).

Until the beginning of the $20^{\text {th }}$ century, the only criteria for happiness was the economic status of people and the growth of a Gross domestic product that determined the level of a nation's happiness. However, in many cases, becoming richer in a country was tantamount to the reduction of social and environmental values. Social inequities in a country and among them soared and all these were represented in the increase in crime, drug abuse, and other social issues. Therefore, adopting other indexes to measure the

\footnotetext{
Corresponding author: Hossein Mirzaei, h_mirzaei@alumnus.tums.ac.ir

1. Department of Governance and Health, Neuroscience Research Center, Tehran University of Medical Sciences, Tehran, Iran

2. HIV/STI Surveillance Research Center, and WHO Collaborating Center for HIV Surveillance, Institute for Futures Studies in Health, Kerman University of Medical Sciences, Kerman, Iran
}

happiness of society became ineluctable. One of the indexes the UN uses to determine the development level of a country is happiness. UN defines happiness as the satisfaction and contentment of every individual of past and present and hope for the future $(2,3)$.

According to the World Happiness Report, happiness is described as a mental consciousness and an overall judgment that can be measured via questioning and is verifiable in large-scale scrolling (2).

The 7th World Happiness Report, which was published in 2019, was written by a group of independent experts acting in their personal capacities. In this report, Iran's ranking among 178 countries was 117 . In this report, six domains of GDP per capita, social support, healthy life expectancy,

$\uparrow$ What is "already known" in this topic:

The present study is the first study to investigate the happiness among Iranian Industrial Workers at the national level.

\section{$\rightarrow$ What this article adds:}

The national mean of happiness score in work communities was calculated to be 141.22 in range 40 to 200 . The level of happiness varied from the highest value 148.97 in Boushehr Province and the lowest 130.39 in Hormozgan Province. 
freedom to make life choices, generosity, perceptions of corruption were measured and compared (2).

A survey of happiness in the workplace in Honduras revealed that happiness in the workplace is correlated with 1) experiencing emotional joy and satisfaction or positive beliefs in a specific case (such as job satisfaction, emotional commitment, experience positive feeling at work) and 2) structures like learning/development, growth, autonomy, and self-educating (4).

In a survey carried out in Thailand on happiness in the workforce in small and medium-sized companies, 3 factors were found to be effective including (1) proper relationship coupled with honesty, altruism, and unity of individuals (2) proper quality of work-life due to positive and peaceful workplace (3) leadership sustaining support, promotion of happiness, and mutual cooperation (5).

A national cross-sectional study was done among 14292 young adults in Iran in 2017 using the Oxford Happiness Questionnaire. In that study, the mean (SD) happiness score for the study sample was $4.09(0.57)$ in a range of 1 to $6(3)$. Another cross-sectional study was done on 1000 adults in Kerman, Iran, in 2017 using the Oxford Happiness Inventory. In that study, the mean (SD) happiness score for the study sample was 43.24 (15.8) in a range from zero to 87(5).

Since it seems that a comprehensive study has not yet been conducted to measure happiness in Iran's work community, the present survey tries to produce an estimate of happiness in the work community.

\section{Methods}

This is a cross-sectional survey study, whose target community was workers and employees of all workplaces in Iran. The statistical sample included 13842 people from 380 workplaces in 31 provinces. Based on a previous study in the Islamic Republic of Iran, the standard deviation of the level of happiness was 0.97 (3), considering the confidence interval as 0.95 and the degree of precision as 0.1 , the sample size was calculated as 360 for each province. For three provinces of Tehran, Khorasan Razavi, and Isfahan we doubled the number of samples due to the bigger number of workers and this would add up to a total of 13600 samples. Sampling was a multistage cluster sampling method.

A list of workshops as sampling units was prepared from the Ministry of cooperatives labor and social welfare and statistical center of Iran. We classified the workshops list according to the size of their employees into 5 categories: $10-49,50-99,100-499,500-999$ and 1000 employees or more. Then the stratified samples were selected randomly from 609 workplaces countrywide, proportional to the size of employees in each province. Workshops with less than 10 employees were excluded from the study. In workshops with 10-49 employees, all of the employees studied. In other Workshops, twenty employees were selected randomly, based on the table of random numbers. If one workshop did not agree to participate in the study, another workshop of the same class would be replaced. Inclusion criteria were legal employees, aged 18 years or above and had informed consent.
This study was done in partnership with the Ministry of cooperatives labor and social welfare. General Directors of Cooperatives, Labor and Social Welfare offices in the provinces were invited to the ministry of cooperatives labor and social welfare and the necessity of performing this survey was explained to them. Then, the Offices of Cooperative, Labor, and Social Welfare were asked to select 2 interviewers in each province.

The tool used for this research was a questionnaire. This questionnaire was composed of two parts; the first part was about the demographic information of people and the second part contains 40 questions which were made by Abachizadeh and Montazeri and were based on their two previous studies $(2012,2015)$ to measure happiness in people living in Tehran $(3,6)$. Based on the results Abachizadeh and Montazeri Cronbach's alpha for internal consistency was estimated to be 0.90 , they calculated the reliability coefficient based on Intra Class Correlation in 100 samples (taken after 10 to 14 days from the first round of sampling) and ICC was estimated to be 0.89 (7).

Two people in each province, who had been trained in a one-day workshop, carried out interviews. Then each participant was made thoroughly aware of the confidentiality of her/his personal information and his/her right to cease to cooperate at any stage of the project and was given the consent form subsequently.

Each of the questions was scored from 1 to 5 (Likert scale), including "Very much $=5$, Much $=4$, Average $=3$, Low $=2$, and Very Low $=1 "$. For questions 13, 14, 25, 26, $29,32,34,38$ the order of answers were reversed to "Very Low $=5$, Low $=4$, Average $=3$, Much $=2$, Very much $=$ $1 "$. The scores of items were added up to provide the whole score of happiness. Therefore, the total happiness score ranges from 40 to 200 . Higher scores indicate an individual's higher level of happiness.

Finally, the collected data were analyzed using SPSS 16 software (SPSS Inc., Chicago, IL). Continuous variables were summarized using mean and standard deviation (SD). Categorical variables were summarized by frequency and percentage. The linear regression method was used to evaluate the adjusted association between predictor variables and happiness score. P-values less than 0.05 were considered as statistically significant. And the charts and tables were prepared to indicate each province's happiness level and the national mean.

\section{Results}

In this survey, 13,842 questionnaires were completed in 380 workplaces in 31 provinces of Iran. The average age of employees was $35.4 \pm 7.78$ years. Majority of the respondents were male $(\mathrm{n}=11835,85.5 \%)$; they had finished middle/secondary school $(\mathrm{n}=7142,51.6 \%)$ and were married $(\mathrm{n}=11323,81.8 \%)$ (Table 1$)$.

The content validity of this questionnaire was verified in a panel of 12 experts of which yielded a content validity index (CVI) of $87 \%$ and a content validity ratio (CVR) of 0.89 . Reliability of the questionnaire determined by using internal consistency. Cronbach's alpha for internal consistency was estimated to be 0.88 . 


\begin{tabular}{lcc}
\multicolumn{2}{l}{ Table 1. Demographic characteristics of the participants (Iran, 2015) } & $\mathrm{n}(\%)$ \\
\hline Variable & Level & $11835(85.5)$ \\
Sex & Male & $2007(14.5)$ \\
Education & Female & $734(5.3)$ \\
& Primary school or lower & $7142(51.6)$ \\
Marital status & Middle school/ high school & $5966(43.1)$ \\
& College or university degree & $2338(16.9)$ \\
Worker's class & Single & $11323(81.8)$ \\
& Married & $181(1.3)$ \\
& Divorced or widow & $8264(59.7)$ \\
& Skilled worker* & $4388(31.7)$ \\
\hline
\end{tabular}

* Any worker who has attended a vocational training program at a high school, college, university, or technical school. ** Applies to jobs with no available institutional training program.

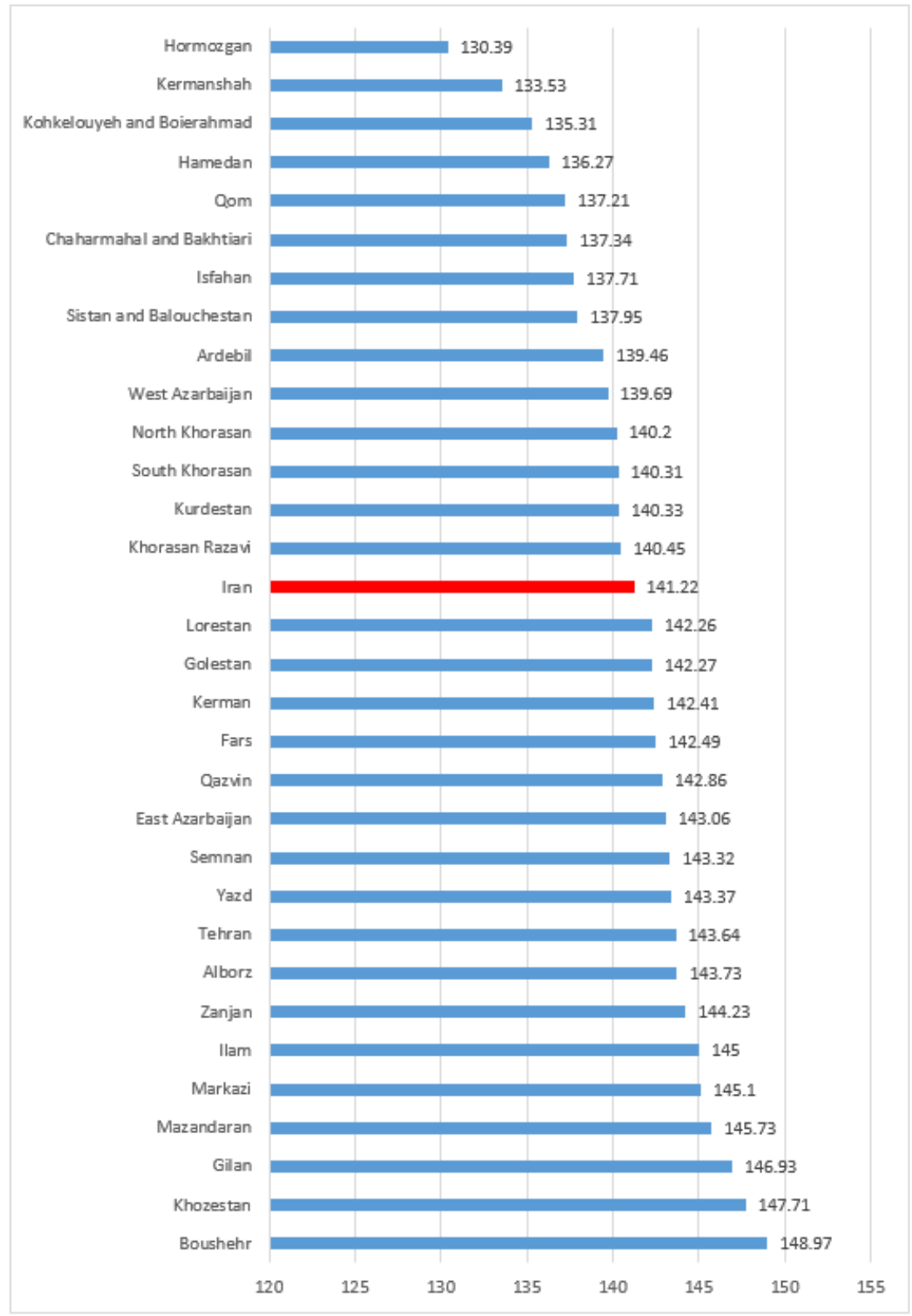

Fig. 1. The average score of Happiness in the work and production community according to province (in the range 40 to 200)

The mean \pm SD of national happiness score in work communities was calculated to be $141.22 \pm 22.89$ (Fig. 1). As is shown in Table 2 and Figure 1, the mean \pm SD value of happiness in Boushehr Province is the highest
(148.97 \pm 21.49$)$ and in Hormozgan is the lowest (130.39 \pm 25.28$)$. Figure 2 shows proveniences with high, medium and low values of happiness score. 
Table 2. The average total score of happiness in the work and production community according to the province

\begin{tabular}{|c|c|c|c|c|}
\hline Province & Sample size & Mean & Standard deviation & $95 \% \mathrm{CI}$ \\
\hline East Azarbaijan & 303 & 143.06 & 22.93 & $120.13-165.99$ \\
\hline West Azarbaijan & 338 & 139.69 & 24.85 & $114.84-164.54$ \\
\hline Ardebil & 336 & 139.46 & 21.96 & $117.5-161.42$ \\
\hline Isfahan & 808 & 137.71 & 23.22 & $114.49-160.93$ \\
\hline Alborz & 303 & 143.73 & 21.17 & $122.56-164.9$ \\
\hline Ilam & 300 & 145 & 24.62 & $120.38-169.62$ \\
\hline Boushehr & 315 & 148.97 & 21.49 & $127.48-170.46$ \\
\hline Tehran & 836 & 143.64 & 20.99 & $122.65-164.63$ \\
\hline Chaharmahal and Bakhtiari & 390 & 137.34 & 21.75 & $115.59-159.09$ \\
\hline South Khorasan & 303 & 140.31 & 19.91 & $120.4-160.22$ \\
\hline Khorasan Razavi & 813 & 140.45 & 22.36 & $118.09-162.81$ \\
\hline North Khorasan & 398 & 140.20 & 22.44 & $117.76-162.64$ \\
\hline Khozestan & 301 & 147.71 & 23.21 & $124.5-170.92$ \\
\hline Zanjan & 300 & 144.23 & 21.63 & $122.6-165.86$ \\
\hline Semnan & 373 & 143.32 & 19.19 & $124.13-162.51$ \\
\hline Sistan and Balouchestan & 300 & 137.95 & 24.90 & $113.05-162.85$ \\
\hline Fars & 300 & 142.49 & 23 & $119.49-165.49$ \\
\hline Qazvin & 384 & 142.86 & 21.46 & $121.4-164.32$ \\
\hline Qom & 302 & 137.21 & 23.30 & $113.91-160.51$ \\
\hline Kurdestan & 300 & 140.33 & 20.51 & $119.82-160.84$ \\
\hline Kerman & 300 & 142.41 & 23.37 & $119.04-165.78$ \\
\hline Kermanshah & 318 & 133.53 & 27.81 & $105.72-161.34$ \\
\hline Kohkelouyeh and Boierahmad & 301 & 135.31 & 24.83 & $110.48-160.14$ \\
\hline Golestan & 300 & 142.27 & 24,23 & $118.04-166.5$ \\
\hline Gilan & 388 & 146.93 & 20.55 & $126.38-167.48$ \\
\hline Lorestan & 305 & 142.26 & 21.23 & $121.03-163.49$ \\
\hline Mazandaran & 303 & 145.73 & 19.96 & $125.77-165.69$ \\
\hline Markazi & 321 & 145.10 & 18.43 & $126.67-163.53$ \\
\hline Hormozgan & 397 & 130.39 & 25.28 & $105.11-155.67$ \\
\hline Hamedan & 398 & 136.27 & 26.30 & $109.97-162.57$ \\
\hline Yazd & 385 & 143.37 & 20.58 & $122.79-163.95$ \\
\hline Iran & 13842 & 141.22 & 22.89 & $118.33-164.11$ \\
\hline
\end{tabular}

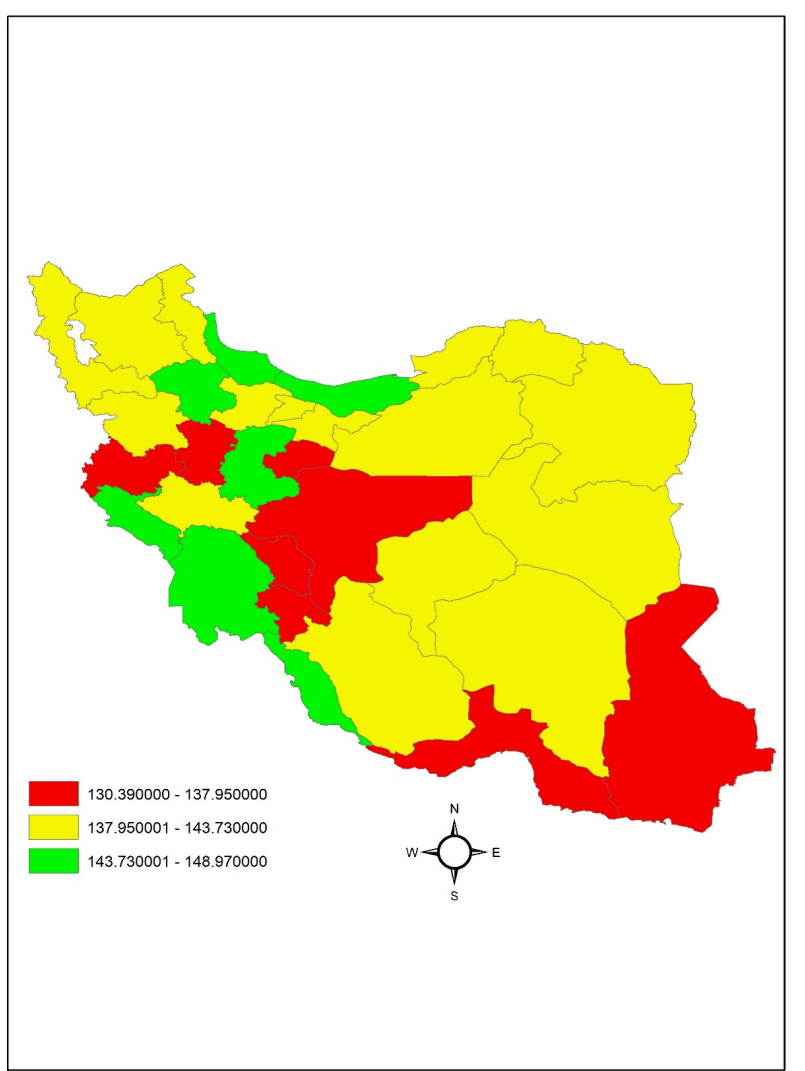

Fig. 2. The score of Happiness in the work and production community according to province

In Table 3, the happiness points per question are demon- strated, and results from analyzing 40 questions of the questionnaire reveal that: 
Table 3. Happiness score of work and production community according to statements

\begin{tabular}{|c|c|c|c|c|}
\hline Statement & & Mean score & $\mathrm{SD}$ & $95 \% \mathrm{CI}$ \\
\hline 1. & I think that physically I am a healthy person & 4.03 & 0.91 & $3.12-4.94$ \\
\hline 2. & I am content with my life as it is. & 4.32 & 0.88 & $3.44-5.20$ \\
\hline 3. & I deal with life conditions. & 4.11 & 0.87 & $3.23-4.98$ \\
\hline 4. & I think a bright future is yet come. & 3.66 & 1.18 & $2.48-4.84$ \\
\hline 5. & I would choose the same life trajectory if I were to live again. & 2.96 & 1.40 & $1.55-4.36$ \\
\hline 6. & I have a good relationship with my family members. & 4.44 & 0.78 & $3.66-5.23$ \\
\hline 7. & Sincere relationship with God creates happiness in me. & 4.50 & 0.81 & $3.68-5.31$ \\
\hline 8. & I think that spiritually I am a healthy person. & 3.97 & 0.92 & $3.04-4.89$ \\
\hline 9. & There is a good reason behind whatever that befalls me (good or bad) & 4.08 & 0.95 & $3.13-5.03$ \\
\hline 10. & I seek specific goals in my life. & 3.94 & 0.93 & $3.00-4.88$ \\
\hline 11. & I am an optimist. & 3.96 & 0.94 & $3.01-4.90$ \\
\hline 12. & My residence is a good place to live. & 3.67 & 1.10 & $2.57-4.77$ \\
\hline 13. & I suffer from multiple physical pains. & 3.46 & 1.21 & $2.24-4.68$ \\
\hline 14. & Life pressure has disagreeable effect on me. & 3.05 & 1.18 & $1.87-4.23$ \\
\hline 15. & Except for my family members, I have a good relationship with people around me. & 3.69 & 1.02 & $2.66-4.72$ \\
\hline 16. & I am content with my work life. & 3.44 & 1.11 & $2.32-4.55$ \\
\hline 17. & I have been a helpful and kind person to others. & 3.77 & 0.85 & $2.91-4.63$ \\
\hline 18. & I believe I am an attractive person in others' eyes. & 3.46 & 0.91 & $2.55-4.38$ \\
\hline 19. & I have enough money to provide for my life. & 2.61 & 1.05 & $1.56-3.66$ \\
\hline 20. & I feel being supported by others. & 2.86 & 1.10 & $1.75-3.96$ \\
\hline 21. & I feel safe where I live now. & 3.76 & 1.02 & $2.73-4.79$ \\
\hline 22. & The society where I live is a good place to live. & 3.40 & 1.16 & $2.24-4.57$ \\
\hline 23. & I have many things in my life to be grateful for. & 4.19 & 0.92 & $3.27-5.11$ \\
\hline 24. & I have achieved whatever I wanted. & 3.03 & 1.08 & $1.95-4.12$ \\
\hline 25. & I feel to be inferior (lower level) to my peers. & 3.33 & 1.01 & $2.22-4.43$ \\
\hline 26. & I feel I am subject to discrimination in the society. & 3.13 & 1.20 & $1.92-4.33$ \\
\hline 27. & I watch my behavior and emotions. & 3.95 & 0.85 & $3.09-8.80$ \\
\hline 28. & I have a great self-confidence. & 3.84 & 0.95 & $2.88-4.79$ \\
\hline 29. & I am a sad person. & 3.47 & 1.01 & $2.46-4.49$ \\
\hline 30 . & I feel I have enough energy for my routine tasks. & 3.98 & 0.94 & $3.03-4.92$ \\
\hline 31. & I enjoy going through my routine. & 3.71 & 1.03 & $2.67-4.74$ \\
\hline 32. & I am an anxious person. & 3.38 & 1.12 & $2.26-4.51$ \\
\hline 33. & I have good night's sleep & 3.80 & 1.02 & $2.77-4.82$ \\
\hline 34. & I feel I am lazy and lethargic. & 3.80 & 1.02 & $2.77-4.82$ \\
\hline 35. & I am at peace with myself. & 3.70 & 0.98 & $2.72-4.68$ \\
\hline 36. & Mentally, I am an alert person. & 4.06 & 0.83 & $3.22-4.90$ \\
\hline 37. & I laugh a lot. & 3.61 & 1 & $2.60-4.61$ \\
\hline 38. & I lose my temper very easily. & 3.12 & 1.07 & $2.04-4.19$ \\
\hline 39. & I do artistic and creative things. & 2.89 & 1.16 & $1.73-4.05$ \\
\hline 40. & I have a sense of humor. & 3.69 & 1.03 & $2.66-4.72$ \\
\hline
\end{tabular}

- The seventh statement, 'sincere relationship with God, creates happiness in me,' with the mean value of 4.5 received the most points and therefore increased the total happiness points.

Among the statements with the least points was the nineteenth one, 'I have enough money to provide for my life', which obtained the mean value of 2.61. These statements had a reductive effect on the total value of happiness. For example, the previous statement demonstrates that satisfaction from meeting the financial needs of life boosts his happiness. The second in this list was the twentieth statement,
'I feel being supported by others', which had the same effect and interpretation.

The adjusted linear regression model showed a significant negative association between happiness and age $(\beta=$ $0.12, p=0.001)$. In addition, female workers had a significantly higher happiness score than male workers $(\beta=1.29$, $\mathrm{p}=0.031$ ), and workers with college or university educational degrees had significantly higher happiness scores than workers with lower educational status $(\beta=7.05$, $\mathrm{p}=0.0001)$. Divorced or widow workers had a significantly lower happiness score than single or married workers $(\beta=$ 9.77, $\mathrm{p}=0.008)$. The skilled workers had a significantly

Table 4. Multiple Linear regression analysis for predictor variables of happiness in Iranian workers (Iran, 2015)

\begin{tabular}{|c|c|c|c|c|}
\hline Variable & Level & Score of Happiness & $\mathrm{B}$ & $\mathrm{p}$ \\
\hline Age & - & - & -0.12 & 0.001 \\
\hline \multirow[t]{2}{*}{ Sex } & Male & $141.06(22.73)$ & Ref & Ref \\
\hline & Female & $144.09(21.88)$ & 1.29 & 0.031 \\
\hline \multirow[t]{3}{*}{ Education } & Primary school or lower & $134.93(25.80)$ & Ref & Ref \\
\hline & Middle school/ high school & $139.48(23.03)$ & 3.59 & 0.0001 \\
\hline & College or university degree & $144.19(21.86)$ & 7.05 & 0.0001 \\
\hline \multirow[t]{3}{*}{ Marital status } & Single & $141.97(23.68)$ & Ref & Ref \\
\hline & Married & $141.25(22.58)$ & 1.53 & 0.008 \\
\hline & Divorced or widow & $130.32(26.23)$ & -9.77 & 0.0001 \\
\hline \multirow[t]{3}{*}{ Worker's class } & Unskilled worker * & $138.22(23.54)$ & Ref & Ref \\
\hline & skilled worker & $142.50(22.28)$ & 2.64 & 0.002 \\
\hline & Other** & $143.26(22.82)$ & 2.95 & 0.0001 \\
\hline
\end{tabular}


higher happiness score than unskilled workers $(\beta=2.64)$ (Table 4).

\section{Discussion}

In this study, the national mean value for happiness in work communities is 141.22 . The mean score of happiness in Tehran, which was estimated by the same questionnaire was slightly higher than the current study. It can happen due to differences in the study population. The study population in the current study was Industrial Workers, but in the study of Abachizadeh and Montazeri in Tehran, the study population was a sample of Tehran population. A study which was done in one of the United Kingdom's largest private employers showed that mean happiness score among 12,282 sale workers was 2.60 (in range of 1-5) (7). Another study, which was conducted in Uganda showed that the mean score of happiness among 900 professional nurses employed in public hospitals in Uganda was 2.18 in the range of 1-6 (8). A study which was conducted in Thailand showed that the mean score of happiness among small and medium-sized enterprises was 3.81 in the range of 1-5 (9). Happiness studies in the workplace in Iran are limited in some jobs like nurses and other healthcare workers. In a study conducted on hospital nurses in Iran, the mean of happiness was 123.4 in the possible score range of 29-174. Khosrojerdi reported moderate level of happiness among nursing students in Iran with a happiness mean score of 123.4(on a 29 to 174 scale) (10). Based on results of another study in an educational hospital in Tabriz, the score of happiness was $64.2 \pm 11.5$ (score range 35 to 116 ), which suggests an average level of happiness among the nurses (11). As shown in here, happiness is different in studies; it can be due to differences in the study group or differences in the occupational groups and time and place of study. Based on our search we did not found happiness study in industrial workplace with same instrument in Iran. In addition, due to difference in work environment between hospital and industrial workplace, we cannot compare happiness score in these environments.

The highest value of happiness score was for Boushehr (148.97), and the lowest value was for Hormozgan (130.39). Happiness score in some provinces (including Bushehr, Khuzestan, Gilan, Mazandaran, Markazi, Ilam, Zanjan, Alborz, Tehran, Yazd, Semnan, east Azerbaijan, Qazvin, Fars, Kerman, Golestan and Lorestan) were higher than the National Happiness score. In some provinces (including Hormozgan, Kermanshah, Kohkelouyeh and Boierahmad, Hamedan, Qom, Chaharmahal and Bakhtiari, Isfahan, Sistan and Balouchestan, Ardebil, West Azerbaijan, North Khorasan, South Khorasan, Kordestan and Razavi Khorasan) were lower than the National Happiness score. This difference between provinces can be due to the combination of different factors. Differences in Human Development Index (HDI), healthy years of life expectancy, religious attitude, Lifestyle, cultural, social, and economic characteristics are some of these factors. These variables alone can't explain the difference between provinces.

Montazeri et al. study conducted in the general population of the country showed that happiness score in Zanjan province was highest and in Yazd province were lowest.
However, in the current study, happiness score were somewhat the same; and in both of them, it was higher than the national mean. This difference can be due to the use of different questionnaires.

In Iran, the working hours per week in the public sector is 44. Permitted hours for personal leave are 84 in a year. Compensation and/or vacation leave is one month in a year (two and a half days a month). Medical leave is up to 4 months in a year, and maternity and pregnancy leave are 9 months. 14 days are stipulated for paternity leave. Attendance leave for the marriage of children or the employee $\mathrm{him} /$ herself would be 7 . Bereavement leave for the immediate family of the employee is 7 days which is only effective within 40 days after the death.

Comparing the Labor Law in Iran with that of countries with the happiest and the most loyal employees, one cannot notice a substantial discrepancy. Therefore, the working hours cannot be a determining factor; however, the pregnancy or medical leave days in Iran are fewer than the same category in those countries, and laws about engaging simple employees in management affairs (like Denmark's) are absent altogether.

The lowest values in our study were assigned to the nineteenth statement, 'I have enough money to provide for my life', which exhibits the pivotal role of the economic factors occupies in our feeling of happiness is consistent with other domestic research findings.

Countries with equitable distribution of income are doing better in happiness index, and today, the most valid and reliable approach to universal health care for developing countries is economic growth accompanied by equitable distribution of income. In order to achieve that, we have to ensure civil rights, collect and redistribute taxes equitably, provide a proper condition for investment, create more jobs and increase the funding for public and higher education and National Policies concerning leisure and recreation in the government's budget (12). The second among the lowest point-receiving statements was number twenty, 'I feel being supported by others', corroborating other findings which assert that not only does social support have a direct impact on health but also is indirectly affecting indexes such as happiness (13). In the present study, the seventh statement, 'sincere relationship with God creates happiness in me', obtained the highest points. This is compatible with the findings of Keshavarz et al. (14) and other studies such as "The Social Context of Wellbeing" carried out in The Royal Society.

According to the 2013 World Happiness Report, the World Index of Happiness was 5.158. Moreover, the North Americans (7.133) and Western Europeans (6.703) were happiest and Sub-Saharans (4.626) and South Asians (4.782) were the least happy people. Measured 4.643, Iran ranked 115 among 156 countries. Losing 0.677 points in value, Iran fell 19 spots from 2007 (13)

According to Business Insider, 10 countries from Western Europe and the European Union are among the happiest employees in the world. Effective factors in holding top spots are working hours, allowed days for medical leave, insurance and health care coverage, public holidays and rewards and incentives, maternity and pregnancy leaves, and 
job stability (10). In the studies carried out in our country, as well, variables such as age, marital status, creativity, job security, work experience, amenities, office amenities, educational facilities, employee involvement and job satisfaction are having a meaningful and direct relationship with happiness in the workplace (8).

Among the countries with the happiest and the most loyal employees are:

1. Denmark: It is the top country in 2016. Thinking of happiness as a priority and placing chairs for ordinary employees in senior management meetings to ensure a fairer distribution of power in companies with more than $35 \mathrm{em}-$ ployees, which endows them with similar rights and authority (power) as senior partners and managers are some of the measures the employers in this country have implemented. Denmark has achieved 7.5 on a scale of $0-10$ in employee happiness. Average working hours there is 37 per week and the employees receive $100 \%$ of her/his wage for 30 days' medical leave a year (11).

2. Norway: This country has obtained 9 out of 10 points for the 'better life' index of the Organization for Economic Co-operation and Development.

3. Sweden: Only one percent of people in Sweden work more than 50 hours a week, and parents can share 480 days parental leave between themselves.

4. Austria: High wages have culminated with a maximum of 5 weeks off and 13 public holidays. A generous pregnancy leave means a woman can take a leave for 8 weeks prior to and 8 weeks following childbirth.

5. Hungary: Workforce in this small country is the happiest in Eastern Europe.

6. Germany: It is mostly considered the industrial hub of Europe. Workers in one of the largest and mightiest economies in the world are working shorter hours but due to the 'hardworking' mindset, they are more productive (11).

In other countries, creating job security via developing international companies, improving supportive regulations in terms of proper working hours, leave salary were of incentives and effective factors in boosting happiness in employees. In Singapore, the competitive salaries and in Colombia, creating multiple job opportunities in the technology sector and start-ups coupled with fast economic growth were some of the effective factors in the happiness and loyalty of employees $(10,11)$.

One of the characteristics of this study, which seems to be the first nation-wide survey of its kind to probe happiness in work communities, is the large size of sampling (13842), and the other is points reporting per province. This in turn, would lead to planning for increasing happiness based on indigenous cultural, social, and industrial features of each region.

Some of the limitations of this study were dishonesty in responding, the discrepancy in comprehending the statements considering the disparate connotation of the lexicon (particularly emotional ones) for each individual, difficulty of expressing one's level of emotion in just one of the options and having personal reasons for hiding some emotions and feelings (11).
Results showed a significant negative correlation between happiness and age, some of the studies were consistent with these funding $(14,15)$, but other studies have shown opposite directions (16). Some other studies showed that the relationship between age and happiness is a $\mathrm{U}$ shape model $(17,18)$.

In this study, happiness score in women was higher than in men. Some studies have shown consistent results (19). In some other studies, happiness was higher in men than in women $(14,15)$. In other studies, there was no significant association between gender and happiness score (5).

Workers with a university education had higher happiness scores than lower educational statuses. Results of most studies showed that people with high education levels have higher happiness scores $(5,19)$. Other studies have shown inconsistent results $(14,16,19)$. People with a high level of education have a high level of self-confidence and self-esteem, which can lead to a high of happiness.

Married workers had higher happiness scores compared with divorced or widowed and single workers. Most studies revealed that marriage is associated with a higher happiness score $(19,20)$. However, the results of a national survey in Iran showed that married people had lower happiness scores than single people (14). This relationship can be due to higher social support and healthier lifestyle of married people.

The skilled worker had, on average, higher happiness scores compared with unskilled workers in the present study. This relationship can be due to the higher income and job security of skilled workers.

\section{Conclusion}

It is necessary for policymakers to take employee happiness as an effective factor in efficiency and productivity. Job security, appropriate interactions, individual and team management, raising salary and perquisites, and more flexibility in working hours and days can be helpful in increasing happiness. Involving the employees in organizational management and empowering them, granting more autonomy to employees for necessary decision-making in their respective departments, and sharing the profit of the organization can lead to the greater happiness of the workers and their organizational loyalty. For Hormozgan, Kermanshah, Chaharmahal and Bakhtiari, Kohgiluyeh and Boyer-Ahmad, and Isfahan which are the least happy province, regional planning based on the indigenous industry/ies and cultural, social, and economic characteristics is recommended.

\section{Acknowledgment}

We would like to express our deep gratitude to the Ministry of Labor, Social Co-operation and Social Welfare's officials Mr. Sadeghifar, Mr. Bostanmanesh, Mr. Sadeghian, and all the CEOs in each province.

\section{Conflict of Interests}

The authors declare that they have no competing interests. 


\section{References}

1. Chaiprasit K, Santidhiraku O. Happiness at work of employees in small and medium-sized enterprises, Thailand. Procedia Soc Behav Sci. 2011 Jan 1;25:189-200.

2. Keith KD, editor. Cross-cultural psychology: Contemporary themes and perspectives. John Wiley \& Sons; 2019 Jul 10.

3. Montazeri A, Tavousi M, Haeri A, Mozaffari R, Naghizadeh Moghari F, Anbari M, et al. Happiness among young adults in Iran: a nationwide cross sectional study. Payesh. 2018;17(4):409-20.

4. Karahasanoglu T, Hamzaoglu I, Baca B, Aytac E, Erenler I, Erdamar S. Evaluation of diverting ileostomy in laparoscopic low anterior resection for rectal cancer. Asian J Surg. 2011;34(2):63-8.

5. Haghdoost AA, Momeni M, Bahraminejad F, Danaei M. Levels and predictors of happiness in the south of the Islamic Republic of Iran. East Mediterr Health J. 2020;26.

6. Veenhof AA, van der Peet DL, Meijerink WJ, Cuesta MA. Defunctioning stoma reduces symptomatic anastomotic leakage after low anterior resection of the rectum for cancer: a randomized multicenter trial. Ann Surg. 2008;247(4):718-9; author reply 9-20.

7. Bellet C, De Neve JE, Ward G. Does employee happiness have an impact on productivity? Saïd Bus School WP. 2019;13.

8. Kawalya C, Munene JC, Ntayi J, Kagaari J, Mafabi S, Kasekende F. Psychological capital and happiness at the workplace: The mediating role of flow experience. Cogent Bus Manag. 2019;6(1):1685060.

9. Chaiprasit K, Santidhiraku O. Happiness at work of employees in small and medium-sized enterprises, Thailand. Procedia Soc Behav Sci. 2011;25:189-200.

10. Khosrojerdi Z, Tagharrobi Z, Sooki Z, Sharifi K. Predictors of happiness among Iranian nurses. Int J Nurs Sci. 2018;5(3):281-6.

11. Javadi Sharif T, Hosseinzadeh M, Mahdavi N, Namdar Areshtanab H, L Dickens G. Happiness and its Relationship with Job Burnout in Nurses of Educational Hospitals in Tabriz, Iran. Int J Commun Based Nurs Midwif. 2020.

12. Matthiessen P, Hallbook O, Rutegard J, Simert G, Sjodahl R. Defunctioning stoma reduces symptomatic anastomotic leakage after low anterior resection of the rectum for cancer: a randomized multicenter trial. Ann Surg. 2007;246(2):207-14.

13. Chude GG, Rayate NV, Patris V, Koshariya M, Jagad R, Kawamoto $\mathrm{J}$, et al. Defunctioning loop ileostomy with low anterior resection for distal rectal cancer: should we make an ileostomy as a routine procedure? A prospective randomized study. Hepatogastroenterology. 2008;55(86-87):1562-7.

14. Montazeri A, Omidvari S, Azin A, Aeenparast A, Jahangiri K, Sadighi $\mathrm{J}$, et al. Happiness among Iranians: findings from the Iranian Health Perception Survey (IHPS). Payesh (Health Monitor). 2012;11(4):46775 .

15. Richards J, Jiang X, Kelly P, Chau J, Bauman A, Ding D. Don't worry, be happy: cross-sectional associations between physical activity and happiness in 15 European countries. BMC Public Health. 2015;15(1):53.

16. Mehrdadi A, Sadeghian S, Direkvand-Moghadam A, Hashemian A. Factors affecting happiness: a cross-sectional study in the Iranian youth. J Clin Diagnos Res. 2016;10(5):VC01.

17. Garaigordobil M. Predictor variables of happiness and its connection with risk and protective factors for health. Front Psychol. 2015;6:1176.

18. Frijters P, Beatton T. The mystery of the U-shaped relationship between happiness and age. J Econ Behav Organ. 2012;82(2-3):525-42.

19. Subramanian S, Kim D, Kawachi I. Covariation in the socioeconomic determinants of self rated health and happiness: a multivariate multilevel analysis of individuals and communities in the USA. J Epidemiol Commun Health. 2005;59(8):664-9.

20. Ergin I, Mandiracioglu A. Demographic and socioeconomic inequalities for self-rated health and happiness in elderly: the situation for Turkey regarding World Values Survey between 1990 and 2013. Arch Gerontol Geriatr. 2015;61(2):224-30. 